\title{
Combination effect of therapies targeting the PI3K- and AR- signaling pathways in prostate cancer
}

\author{
Shalini Singh Yadav ${ }^{1, *}$, Jinyi Li $^{1, *}$, Jennifer A. Stockert ${ }^{1}$, James O'Connor ${ }^{1}$, Bryan \\ Herzog $^{1}$, Cordelia Elaiho ${ }^{1}$, Matthew D. Galsky ${ }^{1,2}$, Ashutosh Kumar Tewari ${ }^{1}$, Kamlesh \\ Kumar Yadav ${ }^{1}$ \\ ${ }^{1}$ Department of Urology, Icahn School of Medicine at Mount Sinai, New York, NY 10029, USA \\ ${ }^{2}$ Division of Hematology and Medical Oncology, Icahn School of Medicine at Mount Sinai, New York, NY 10029, USA \\ *These authors have contributed equally to this work \\ Correspondence to: Shalini Singh Yadav, email: shalini.singh@mountsinai.org \\ Ashutosh Kumar Tewari, email: ash.tewari@mountsinai.org \\ Kamlesh Kumar Yadav, email: kamlesh.yadav@mountsinai.org
}

Keywords: prostate cancer, drug-resistance, drug combination, synergy, antagonism

Received: January 28, $2016 \quad$ Accepted: October 01,2016 Published: October 20, 2016

\section{ABSTRACT}

Several promising targeted-therapeutics for prostate cancer ( $\mathrm{PCa}$ ), primarily affecting the androgen receptor (AR) and the PI3K/AKT/mTOR-pathway, are in various phases of development. However, despite promise, single-agent inhibitors targeting the two pathways have not shown long-term benefits, perhaps due to a complex compensatory cross talk that exists between the two pathways. Combination therapy has thus been proposed to maximize benefit. We have carried out a systematic study of two-drug combination effect of MDV3100 (AR antagonist), BKM120 (PI3K inhibitor), TKI258 (pan RTK inhibitor) and RAD001 (mTOR inhibitor) using various PCa cell lines. We observed strong synergy when AR-positive cells are treated with MDV3100 in combination with any one of the PI3K-pathway inhibitors: TKI258, BKM120, or RAD001. Growth curve based synergy determination combined with Western blot analysis suggested MDV3100+BKM120 to be the most effective in inducing cell death in such conditions. In the case of dual targeting of the PI3Kpathway BKM120+TKI258 combination displayed exquisite sensitivity in all the 5 cell lines tested irrespective of androgen sensitivity, (LNCaP, VCaP, 22Rv1, PC3 and Du145). The effect of blockade with BKM120+TKI258 in PC3 cells was similar to a combination of BKM120 with chemotherapy drug cabazitaxel.

Taken together, our observation supports earlier observations that a combination of AR-inhibitor and PI3K-inhibitor is highly synergistic. Furthermore, combining BKM120 with TKI258 has better synergy than BKM120+RAD001 or RAD001+TKI258 in all the lines, irrespective of androgen sensitivity. Finally, BKM120 also displayed synergy when combined with chemotherapy drug cabazitaxel. No antagonism however was observed with any of the drug combinations.

\section{INTRODUCTION}

Prostate cancer $(\mathrm{PCa})$ is the most common cancer in American men and the second-leading cause of the approximately 28,000 cancer-related deaths each year [1]. Although initially responsive to androgen deprivation therapy (ADT), nearly all metastatic PCa progress to a castrate-resistant prostate cancer (CRPC) phase with poor prognosis [2]. Although some CRPCs respond to chemotherapeutic drugs, like docetaxel [3] or cabazitaxel [4], the benefit is limited and often short-lived. Recent studies have cemented earlier observations that deregulation of androgen-receptor (AR) signaling and the $\mathrm{PI} 3 \mathrm{~K} / \mathrm{AKT} / \mathrm{mTOR}$ pathways 
play important roles in carcinogenesis, progression and development of resistance [5-7].

The AR-signaling pathway has been the main therapeutic target for more than 70 years and ADT shows remarkable beneficial effect in controlling the early phase of the disease. Studies directed towards understanding the mechanism of CRPC development identified upregulation of AR-signaling in more than $60 \%$ of CRPCs, either through overexpression, mutation or AR splice-variant production [8]. This prompted the development of new AR-signaling blockers Enzalutamide and Abiraterone, both of which recently acquired FDA approval [9-12]. Since Enzalutamide directly binds and inhibits AR function it has also been approved for treatment-naïve patients [11].

The PI3K-AKT-mTOR pathway on the other hand is important for normal growth and survival of the cell. It has been shown to be upregulated in $30-50 \%$ of all prostate cancers [13]. PTEN alone is lost in more than $40 \%$ of highly lethal CRPCs [14] and around 15\% of primary prostate cancer [7]. Thus, small molecule inhibitors targeting critical members of this pathway are in various stages of development or clinical trials, including BKM120 [15], TKI258 [16] and RAD001 [17]. Whereas BKM120 (a PI3K inhibitor) and RAD001 (an mTOR inhibitor) directly inhibit key members of the PI3K-pathway, TKI258 is a pan-receptor tyrosine kinase inhibitor (targeting FGFR, VEGFR, PDGFR, etc) that has been shown in breast and colorectal cancer models to act primarily through inhibition of the PI3K-pathway signaling $[18,19]$.

Despite the availability of the new targetedchemotherapeutics, treatment of patients is impeded by the emergence of drug resistance. For instance, CRPC patients on enzalutamide therapy develop resistance within 2 years [20] and single agent RAD001 and BKM120 treatment have failed clinical trials [21, 22]. Remarkably, a crosstalk between the AR- and PI3Kpathway has been established where the loss of AR leads to upregulation of the PI3K-signaling pathway, suggesting a need for simultaneous targeting of both the pathways $[23,24]$. Indeed, combination therapy regimens in breast cancer, another hormone-dependent system, have shown not only to improve therapeutic efficacy and reduce drug toxicity but also delay drug resistance development [25]. In PCa combined inhibition of AKT (with AZD5363) and AR (with MDV3100 or bicalutamide) has been shown to be effective in delaying $\mathrm{PCa}$ progression in preclinical models [26, 27]. However, with several different drugs targeting different members of the PI3K-signaling cascade, a robust and facile method of determining the best synergistic combination is required. Moreover, determining the nature of interaction of two drugs to be combined is essential in making therapeutic choices for the most favorable outcome. Some drug combinations can be antagonistic and would require more of each drug to achieve similar outcomes [28]. Or, they can synergize and increase each others' effect thus requiring lower overall dose and lesser toxicity [29]. Finally, identifying the critical targeting node in a signaling pathway will enable designing better combination for complete pathway inactivation. In the era of precision medicine, identifying the complex nature of drug interaction will be helpful in formulating treatment regimens that are appropriate and likely to prolong remission.

In this study we used an AR antagonist and several PI3K-pathway inhibitors (Figure 1) targeting various nodes of the complex signaling pathway and tested their as single agents or in combination in several prostate cancer cell lines. The WST-1 assay in combination with the CompuSyn algorithm and western blot analyses were utilized to compute and validate the combination indices (CI) of combined-treatment effect of Enzalutamide (MDV3100, AR antagonist), Dovitinib (TKI-258, pan RTK inhibitor), Buparlisib (BKM120, pan PI3K inhibitor), Everolimus (RAD001, mTOR inhibitor) and chemotherapy drug Cabazitaxel in different PCa cell lines. Not only does our data confirm previous observations of combining AR- and PI3K-pathway inhibition for better efficacy, it identifies the targeting node on the PI3K axis for maximal inhibitory effect. Our study also identified that dual targeting of upstream targets (such as receptor tyrosine kinases) with an AKT level blockade (with PI3K inhibitor) is most synergistic.

\section{RESULTS}

\section{Single-agent drug treatment}

We began by testing the sensitivity of the PCa cell lines to single-agent treatments. For this, we generated the dose-response curves and calculated the $\mathrm{IC}_{50}$ values of single-agent inhibitors in LNCaP (Supplementary Figure S2), PC3 (Supplementary Figure S3) and 22Rv1 (Supplementary Figure S4) and Table 1. In LNCaP cells, the $\mathrm{IC}_{50}$ value determined for MDV3100 was relatively high at around $6.31 \mu \mathrm{M}$ similar to what has previously been reported $[23,30]$. However, the $\mathrm{IC}_{50}$ values for TKI258, BKM120 and RAD001 were $3.4 \mu \mathrm{M}, 3.23 \mu \mathrm{M}$ and $4.05 \mu \mathrm{M}$ respectively. In the case of PC3 cells, $\mathrm{IC}_{50}$ values for TKI258, BKM120 and RAD001 were determined to be $2.57 \mu \mathrm{M}, 2.81 \mu \mathrm{M}$ and, $5.46 \mu \mathrm{M}$ respectively. The increased $\mathrm{IC}_{50}$ in the case of RAD001 is perhaps due to the inactivation of PTEN in both LNCaP and PC3 cells (via either frameshift mutation or homozygous deletion, respectively), which drives constitutive PI3K-pathway activation. Indeed, 22Rv1 cells, which express wildtype PTEN, have increased sensitivity to RAD001 at $1.57 \mu \mathrm{M}$ and BKM120 at $1.7 \mu \mathrm{M}$ (Supplementary Table S1 and Supplementary Figure S4), similar to that reported with CH5132799, another mTOR inhibitor in the same cell line [31]. 
To test whether each of the drugs was able to physiologically inhibit its intended target, western blot analysis was performed on whole-cell lysates from PCa cells treated acutely for 1 day with a high concentration $\left(2 \mathrm{xIC}_{50}\right)$ of the drugs. This treatment was done to exclude the physiological effect of pathway inhibition (cell death, altered growth profile, etc) from the direct effect of signaling block. LNCaP cells treated with MDV3100 displayed loss of PSA expression, Figure 2 (lane 2). Whereas BKM120 treatment resulted in almost complete loss of AKT phosphorylation, the effect was partial with TKI258 treatment, Figure 2 (lanes 3 and 4). Treatment with RAD001 led to the complete loss of S6 phosphorylation without affecting AKT phosphorylation, Figure 2 (lane 5). Similar results were observed in other PCa cell lines; VCaP, (Figure 2), PC3, 22Rv1 and Du145 (Figure 4). These observations are consistent with expected response of downstream effectors upon the inhibition of upstream targets, Figure 1.

\section{Combination treatment}

To identify whether a drug combination was synergistic, the combination index (CI) of each drug-pair was calculated. For this, cells were treated with seven inhibitor combination ratios, taking three concentrations above, and three below the approximate $\mathrm{IC}_{50}$ value of each drug as described in the Methods section. Thereafter, using survival data generated from the WST-1 assays, CI-Fa, isobologram and dose-response plots were generated for each drug-pair. To identify whether a drug combination had a synergistic or antagonistic effect, each above-mentioned factor was integrated using the CompuSyn algorithm and CI values were calculated, both at Fa 0.5 (50\% cell death) and Fa 0.8 (80\% cell death), Table 2. CI values less than 1 denotes synergism and greater than 1 antagonism. Finally, the fold changes affected due to the drug-combinations were also tabulated, Supplementary Table S1.

\section{Targeting both AR and PI3K pathways simultaneously}

The dependency of PCa on AR- and PI3Kpathways provides an ideal therapeutic opportunity for a combination treatment that inhibits both the pathways simultaneously. Indeed, when LNCaP cells were treated with AR antagonist MDV3100 in combination with a PI3K pathway inhibitor (TKI258, BKM120 or RAD001) various levels of synergy were observed. The strongest synergism was observed for MDV3100+RAD001 (CI 0.11), followed by MDV3100+BKM120 (CI 0.26), and finally MDV3100+TKI258 (CI 0.33). Remarkably, in the case of MDV3100+RAD001 treatment, synergy was observed even at highest concentration with $\mathrm{Fa} 0.7$ and $\mathrm{Fa} 0.8$ points in the isobologram segregated at the origin, Figure 3i. Moreover, the CI-Fa plot showed all points to be close to the horizontal axis at all concentrations, Figure $3 \mathrm{~h}$. This was in contrast to MDV3100+TKI258 combination where at high drug concentration, the curve tended towards additive $(\mathrm{CI}=1)$, Figure $3 \mathrm{~b}$ and Table 2. Furthermore, whereas in the case

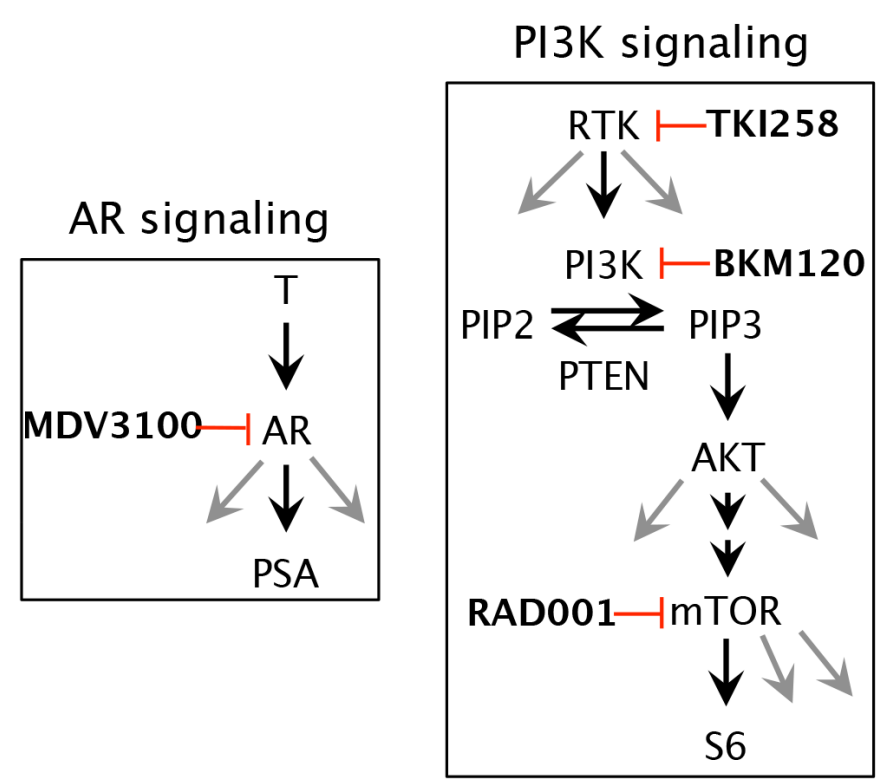

Cell lines used in the study

\begin{tabular}{|l|c|c|}
\hline & AR & PTEN \\
\hline LNCaP & + & - \\
\hline VCaP & + & + \\
\hline CWR22Rv1 & + & + \\
\hline Du145 & - & + \\
\hline PC3 & - & - \\
\hline
\end{tabular}

Figure 1: Schematic of the molecular targets of the drugs and the cell lines chosen in the study. T, testosterone; AR, androgen receptor; PSA, prostate specific antigen; MDV3100 (enzalutamide), (RTK, receptor tyrosine kinase; PI3K, phosphoinositide-3 kinase; PIP2, Phosphatidylinositol (4,5)-bisphosphate; PIP3, Phosphatidylinositol (3,4,5)-trisphosphate; PTEN, Phosphatase and tensin homolog /phosphatidylinositol-3,4,5-trisphosphate 3-phosphatase; AKT, a serine/threonine protein kinase, mTOR, mammalian target of rapamycin; TKI258 (Dovitinib, pan RTK inhibitor); BKM120 (buparlisib, PI3K inhibitor); RAD001 (everolimus, mTOR inhibitor). 
of MDV3100+RAD001 this translated to a 90 and 19 fold reduction in drug dose for MDV3100 and RAD001 respectively to achieve $50 \%$ inhibition as compared to single-agent treatment, in the case of MDV3100+TKI258 or MDV3100+BKM120, the synergistic effects were equivalent to a reduction of drug dose by 42 and 7, and 57 and 7 folds respectively, Table 3 . Analysis of the doseresponse curves generated upon combining MDV3100 with TKI258, BKM120 or RAD001 in LNCaP cells (Figure 3, first column) suggested the best shift to be generated upon BKM120 or RAD001 combination, Figure 3g. To determine the best combination between MDV3100+BKM120 and MDV3100+RAD001, we carried out western blot analysis upon 1-day treatment with various drug-combinations at $2 \mathrm{x} \mathrm{IC}_{50}$ concentrations. The drug concentration was chosen to make comparison consistent with single agent treatment. The level of downstream effector inhibition and cleaved poly ADP ribose polymerase 1 (cPARP1), shown to be a robust read out for apoptosis [32], upon treatment was evaluated. Remarkably, contrary to the CI values, the level of cPARP1 was much higher in cells treated with MDV3100+BKM120 compared to cells treated with MDV3100+RAD001, Figure 2 (left, lane 6, 7 and 8). Grown in charcoal stripped media (to mimic castrate conditions) also showed similar results, Supplementary Figure S5. This could be a ramification of acute treatment of the cells, or perhaps MDV3100+RAD001 induces more of a cytostatic effect whereas MDV3100+BKM120 induces apoptosis. Further experiments are required to differentiate between these two effects. The same effect was observed in the AR positive cell line $\mathrm{VCaP}$ when treated similarly Figure 2 (right, lanes 6,7 and 8). We further validated this observation in another AR-positive but CRPC cell line 22Rv1, which expresses a combination of full-length and a splice variant form of AR that lacks the ligand-binding domain making it insensitive to anti-androgens [33]. Similar to observations in $\mathrm{LNCaP}$ and $\mathrm{VCaP}$ cells, MDV3100+BKM induced higher levels of cPARP1 in 22Rv1 cells when compared to

Table 1: IC50 of single inhibitor treatment $(\mu M)$

\begin{tabular}{lccccc}
\hline & MDV3100 & TKI258 & BKM120 & RAD001 & Cabazitaxel \\
\hline LNCaP & $6.31 \pm 2.03$ & $3.04 \pm 1.20$ & $3.23 \pm 1.32$ & $4.05 \pm 1.51$ & $1.87 \pm 1.17$ \\
PC3 & nd & $2.57 \pm 1.26$ & $2.81 \pm 1.15$ & $5.46 \pm 1.41$ & $6.31 \pm 1.34$ \\
22Rv1 & $237.4 \pm 3.8$ & $4.38 \pm 1.19$ & $1.7 \pm 1.23$ & $1.57 \pm 1.44$ & nd \\
\hline
\end{tabular}

nd $=$ not determined

\section{LNCaP}
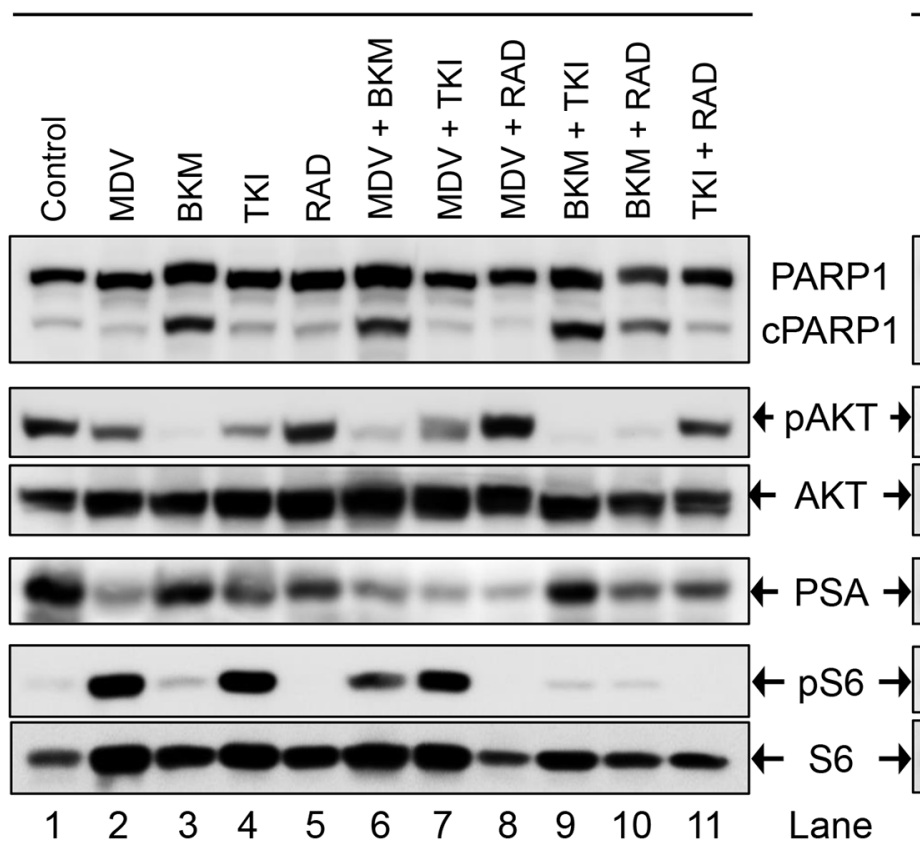
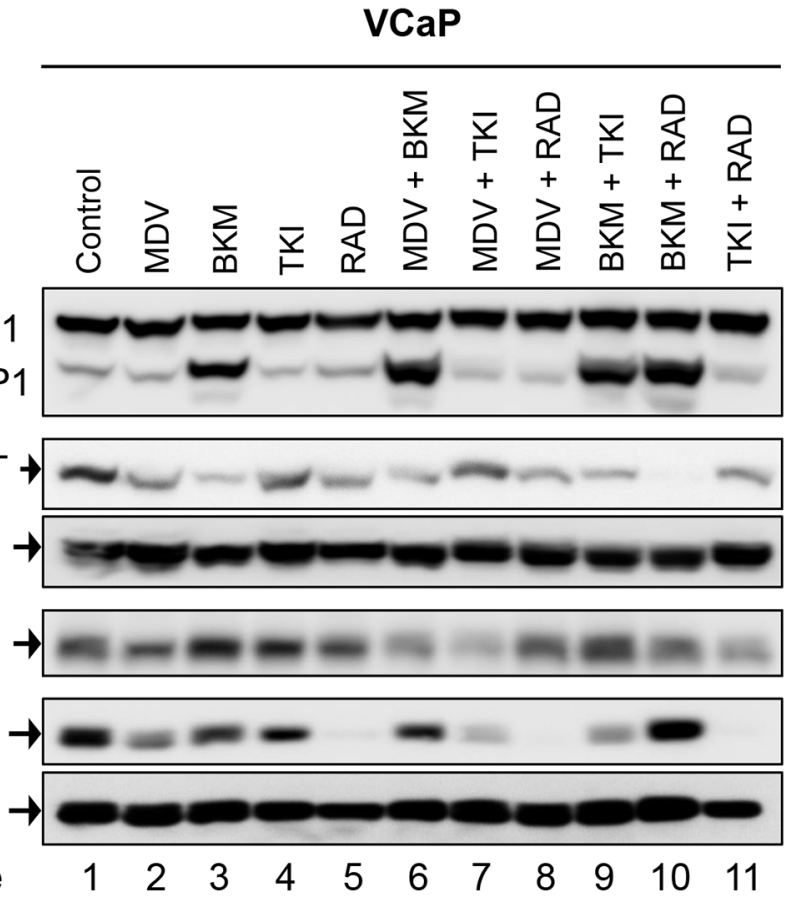

Figure 2: Biochemical effect of perturbations with various drugs, affecting the AR-and PI3K-signaling pathways, and their two-drug combinations in two PCa lines; LNCaP (left), and VCaP (right). Acute signaling blockage was generated by

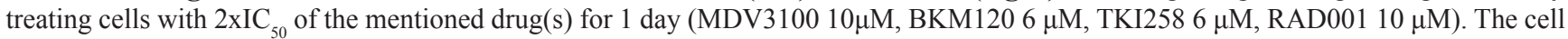
lysate of the treated cells was subjected to western blot analysis using the indicated antibodies. 
Table 2: CI values of combination treatment $(\mathrm{Fa}=0.5 / 0.8)$

\begin{tabular}{lccccccccc}
\hline & $\begin{array}{c}\text { MDV- } \\
\text { TKI }\end{array}$ & MDV-BKM & MDV-RAD & $\begin{array}{c}\text { TKI- } \\
\text { BKM }\end{array}$ & TKI-RAD & BKM-RAD & $\begin{array}{c}\text { Cab- } \\
\text { BKM }\end{array}$ & Cab-TKI & $\begin{array}{c}\text { Cab- } \\
\text { RAD }\end{array}$ \\
\hline LNCaP & $0.33 / 0.74$ & $0.26 / 0.37$ & $0.11 / 0.19$ & $0.20 / 0.28$ & $0.19 / 0.28$ & $0.34 / 0.35$ & $0.46 / 0.49$ & $0.58 / 0.93$ & $0.74 / 0.77$ \\
PC3 & & & & $0.77 / 1.14$ & $0.65 / 0.68$ & $0.54 / 0.77$ & $0.47 / 0.83$ & $0.59 / 0.63$ & $0.72 / 0.88$ \\
22Rv1 & & & & $0.73 / 0.67$ & $0.4 / 0.88$ & $0.41 / 0.36$ & & & \\
\hline
\end{tabular}

Synergy $<1$, Additive 1, Antagonistic $>1$

MDV3100 combinations for PC3 and 22Rv1, and Cabazitaxel combinations for 22Rv1, were not determined

MDV3100+TKI258

a

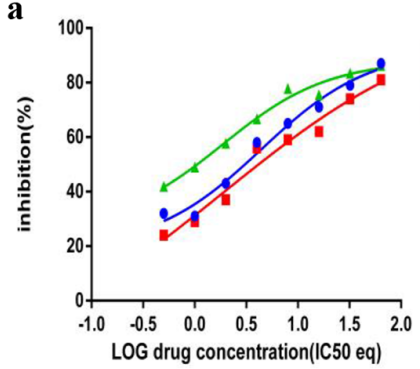

b

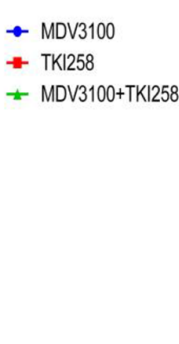

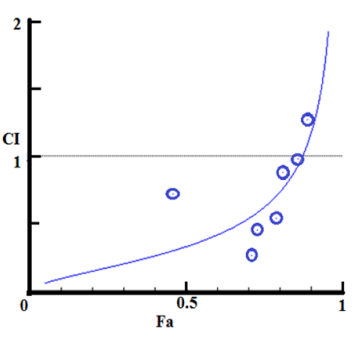

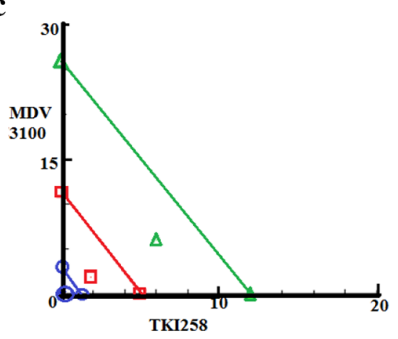

을 $\mathrm{Fa}=0.5$ (1)

MDV3100+BKM120

d

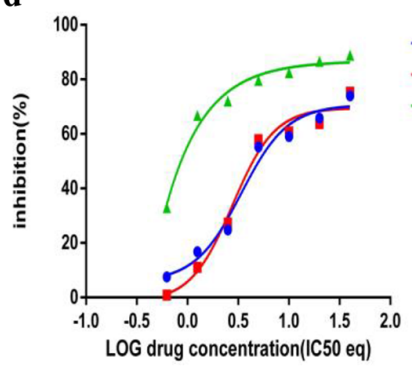

- MDV3100

- BKM120

- MDV3100+BKM120

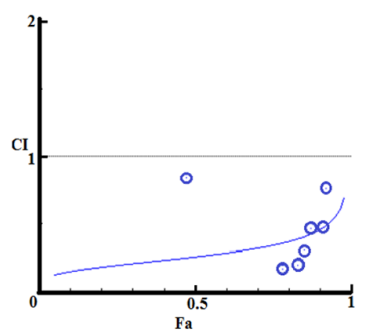

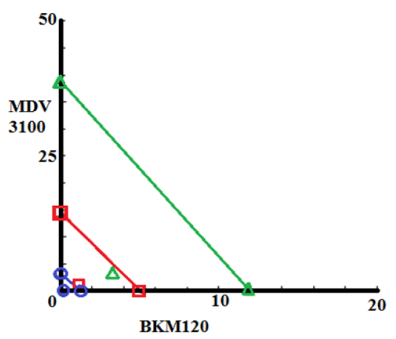

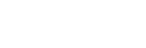

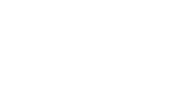

.

\section{MDV3100+RAD001}

g

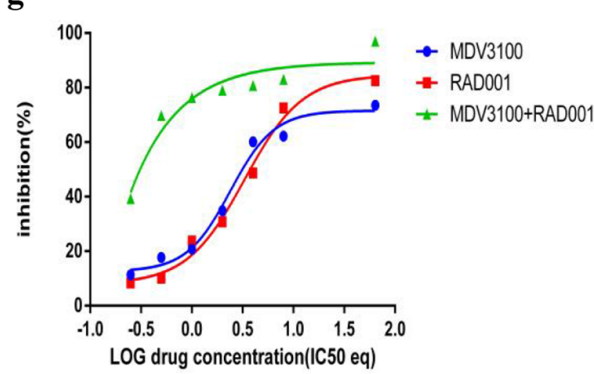

h

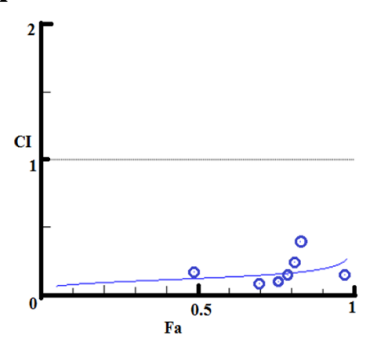

i

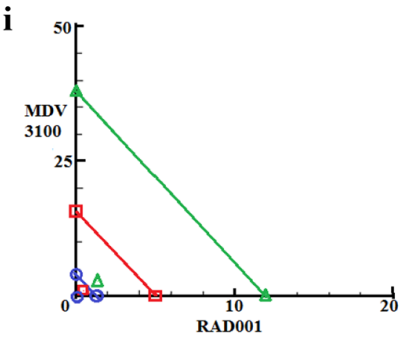

$\begin{aligned} \circ \mathrm{Fa} & =0.5 \\ \square \mathrm{Fa} & =0.7\end{aligned}$

$\begin{aligned} \square & \mathbf{F a}=0.7 \\ \triangle \mathbf{F a} & =\mathbf{0 . 8}\end{aligned}$

Figure 3: Combination effect of therapies targeting the AR- and PI3K pathway. LNCaP cells were treated with the indicated combination of the drugs and analyzed as described in Methods and Supplementary Figure S1. Left column (a, d and g): Curve shift analysis. Degree of left shifted indicated the amount of synergism with the indicated drug-combination. Middle column (b, e and $\mathbf{h})$ : FaCI plot. Blue values above the gray horizontal 'additive' line indicates trends towards antagonism. Low CI values with increased in Fa values suggest better compatibility and high synergism between the drugs. Right column (c, $\mathbf{f}$ and $\mathbf{i})$ : Isobolograms: The green, red and blue lines indicate where the theoretical additive line is for a particular Fa value (here, green, Fa 0.8, red Fa 0.7 and blue Fa 0.5 . The closer the calculated values fall towards the origin, the greater the synergy between the drugs. 
Table 3: IC50 value $(\boldsymbol{\mu M})$ of combination treatment and drug-dose reduction $(\mathrm{Fa}=0.5)$

\begin{tabular}{|c|c|c|c|c|c|c|c|c|c|c|c|c|c|c|c|c|c|c|c|}
\hline & & $\begin{array}{r}\text { MDV } \\
\text { TK }\end{array}$ & $\begin{array}{l}3100- \\
258\end{array}$ & $\begin{array}{r}\text { MDV } \\
\text { BKN }\end{array}$ & $100-$ & $\begin{array}{r}\text { MDV } \\
\text { RAA }\end{array}$ & $\begin{array}{l}3100- \\
001\end{array}$ & $\begin{array}{l}\text { TK } \\
\text { BK }\end{array}$ & $\begin{array}{l}258- \\
1120\end{array}$ & $\begin{array}{l}\text { TK } \\
\text { RA }\end{array}$ & $\begin{array}{l}258- \\
0001\end{array}$ & $\begin{array}{r}\text { BKI } \\
\text { RAI }\end{array}$ & $\begin{array}{l}120- \\
001\end{array}$ & $\begin{array}{l}\text { Caba } \\
- \text { BK }\end{array}$ & $\begin{array}{l}\text { zitaxel } \\
\text { M120 }\end{array}$ & $\begin{array}{r}\text { Cab: } \\
-\mathrm{Tl}\end{array}$ & $\begin{array}{l}\text { zitaxel } \\
\text { I258 }\end{array}$ & $\begin{array}{r}\text { Caba } \\
-\mathbf{R A}\end{array}$ & $\begin{array}{l}\text { zitaxel } \\
\text { D001 }\end{array}$ \\
\hline \multirow{2}{*}{ LNCaP } & $\begin{array}{l}\text { Combination } \\
\text { IC50 }\end{array}$ & 0.15 & 0.46 & 0.11 & 0.35 & 0.07 & 0.21 & 0.32 & 0.32 & 0.33 & 0.33 & 0.60 & 0.60 & 0.89 & 0.45 & 0.35 & 0.70 & 0.64 & 1.29 \\
\hline & $\begin{array}{l}\text { Fold } \\
\text { reduction }\end{array}$ & 42.07 & 6.61 & 57.36 & 9.23 & 90.14 & 19.29 & 9.50 & 10.09 & 9.21 & 12.27 & 5.38 & 6.75 & 2.02 & 7.18 & 5.14 & 4.34 & 2.81 & 3.14 \\
\hline \multirow{2}{*}{ PC3 } & $\begin{array}{l}\text { Combination } \\
\text { IC50 }\end{array}$ & & & & & & & 1.24 & 0.82 & 1.73 & 0.86 & 1.64 & 0.65 & 1.41 & 0.71 & 1.31 & 0.99 & 2.01 & 2.01 \\
\hline & $\begin{array}{l}\text { Fold } \\
\text { reduction }\end{array}$ & & & & & & & 2.08 & 3.44 & 1.49 & 6.35 & 1.72 & 8.40 & 4.48 & 3.97 & 4.82 & 2.61 & 3.14 & 2.72 \\
\hline \multirow{2}{*}{ 22Rv1 } & $\begin{array}{l}\text { Combination } \\
\text { IC50 }\end{array}$ & & & & & & & 0.09 & 0.15 & 0.57 & 0.2 & 0.01 & 0.04 & & & & & & \\
\hline & $\begin{array}{l}\text { Fold } \\
\text { reduction }\end{array}$ & & & & & & & 10.78 & 1.53 & 4.96 & 5.1 & 6.00 & 5.75 & & & & & & \\
\hline
\end{tabular}

MDV3100 combinations for PC3 and 22Rv1, and Cabazitaxel combinations for 22Rv1, were not determined

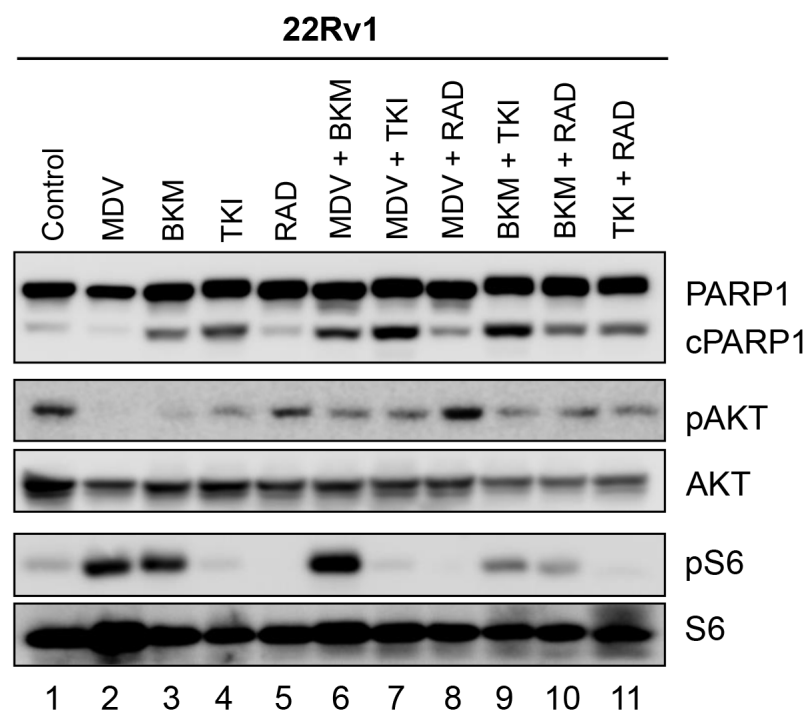

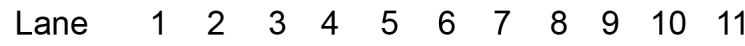

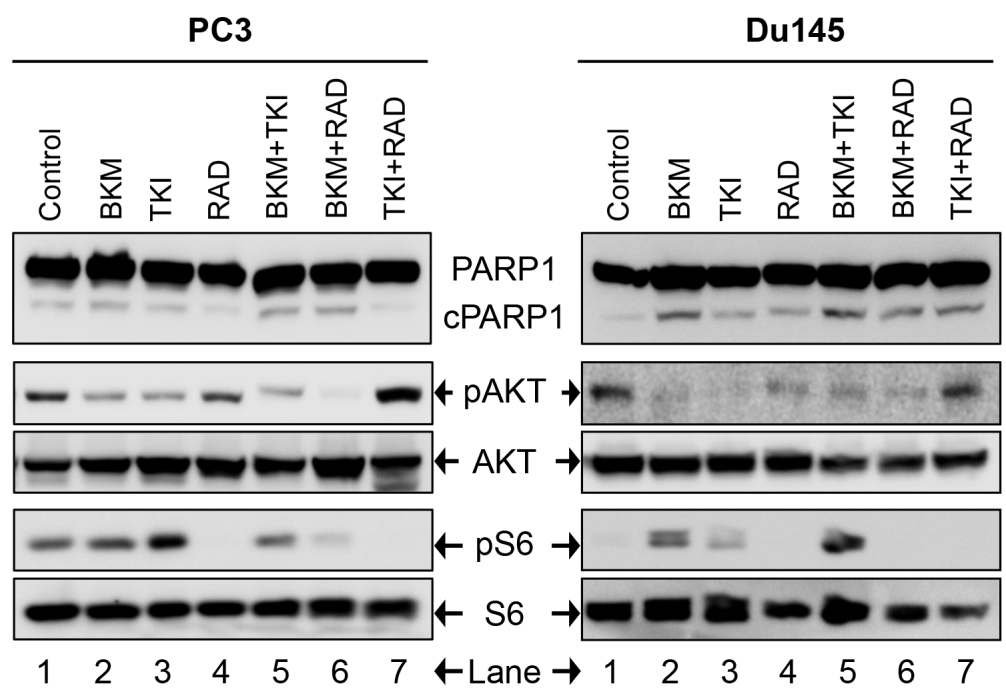

Figure 4: Biochemical effect of perturbations with various two-drug combinations in three CRPC PCa lines: 22Rv1, PC3, and Du145. Cells were treated and analyzed in Figure 2. 
MDV3100 or BKM120 alone, Figure 4 (lane 6). However, we observed a slightly higher level of cell death induced with the MDV3100+TKI258 combination, Figure 4 (lane 7). Perhaps the cells are still wired, in part, for survival through the full-length AR signaling pathway and signaling upstream of PI3K. Taken together, this indicates that combining MDV3100 with BKM120 is highly synergistic. This finding is in line with earlier observations where a combination of MDV3100 with CH5132799 (an AKT inhibitor) was shown to be effective in delaying resistance development in preclinical models of $\mathrm{PCa}[26,27]$.

\section{Combined targeting of PI3K pathway}

More than $49 \%$ of the somatic alteration in metastatic CRPC [6] and around $23 \%$ in primary $\mathrm{PCa}$ have been associated directly with the PI3K pathway [7] underscoring the dependence of $\mathrm{PCa}$ on this pathway. Since the pathway is multi-nodal, identifying the correct combination is crucial for effective abrogation of the pathway in relation to PCa. To achieve this we combined BKM120+TKI258, BKM120+RAD001 and TKI258+RAD001 and tested their effect on various PCa cell lines. When $\mathrm{LNCaP}$ cells were treated with combinations of BKM120+TKI258, BKM120+RAD001 or TKI258+RAD001, we observed CI values of 0.20. 0.19 and 0.34 , respectively, Table 2 . Remarkably, the $\mathrm{CI}$ at $\mathrm{Fa} 0.8$ remained similar to $\mathrm{Fa} 0.5$ in this cell line for all the combinations, Table 2 and Figure 6 middle column, suggesting the drugs to be well tolerated for high drug combinations. However, between the three, the least amount of synergism was observed for the TKI258+RAD001 combination, which was confirmed with western blot analysis where the levels of cPARP were least, when compared to BKM120+TKI258 BKM120+RAD001 levels, Figure 2 (lane 11). This was also observed when VCaP cells were treated similarly. However, whereas in $\mathrm{VCaP}$ cells both BKM120+TKI258 and BKM120+RAD001 combinations led to increased cPARP1 levels, it was only observed with the BKM120+TKI258 combination in LNCaP cells,

a

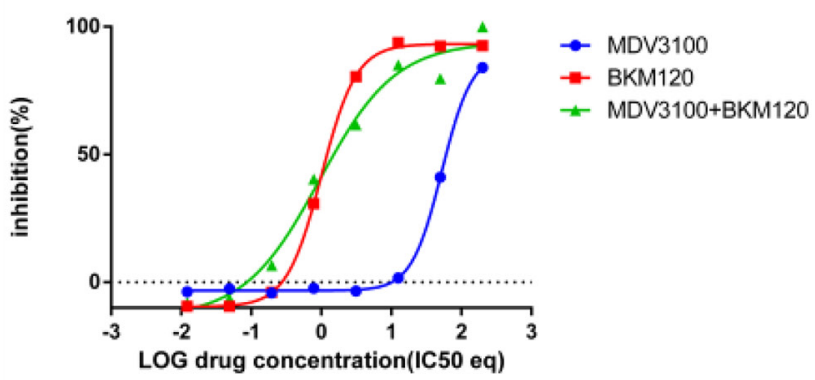

Figure 2 (lane 9, 10). Although both BKM120+TKI258 and BKM120+RAD001 exhibited very similar increases in cPARP1 levels, in VCaP cells, the level of S6 activation, only in the case of BKM120+TKI258, was similar to LNCaP cells treated similarly, Figure 2 (lanes 10, 11). The increased sensitivity of VCaP cells to BKM120+RAD001 combination is perhaps due to its intact PI3K-signaling when compared to LNCaP cells that have inactive PTEN resulting in upregulation of the pathway. The increase in S6 activation in VCaP cells upon BKM120+RAD001 treatment, when compared to $\mathrm{LNCaP}$ cells treated similarly needs further investigation. Taken together, however, our experiments suggest BKM120+TKI258 to be the combination treatment of choice to bring about the most synergy with complete PI3K pathway inhibition.

We next looked at the effect of drug-combination in CRPC lines. In the case of PC3 cells, treatment with BKM120+TKI258, BKM120+RAD001 or TKI258+RAD001 yielded CI value of $0.77,0.65$ and 0.54 , respectively (Table 2 and Figure 7), suggesting high to moderate levels of synergy. However, unlike LNCaP cells, the CI-Fa plots in PC3 cells displayed a trend towards additive and beyond, especially at higher Fa values, Figure 7 (middle column). This was particularly prominent for the BKM120+TKI258 combination (Figure 7h) and was reflected in the highest CI (Fa 0.8 ) value of 1.14 (Table 2). To test if PC3 cells treated with the combination of BKM120+TKI258 would result in the greatest increase in cPARP1 levels, as previously observed in $\mathrm{LNCaP}$ and $\mathrm{VCaP}$ cells, we carried out western blot analysis upon treatment with the various drug combinations. As seen in Figure 4 (lanes 5 and 6) for PC 3 cells, the most prominent cPARP1 bands observed were from cells treated with combinations of BKM120+TKI258 or BKM120+RAD001. To test if this was a consistent trend, we treated two other CRPC cells, 22Rv1 and Du145, both of which do not respond to AR antagonists. Consistent with results from $\mathrm{LNCaP}$ and $\mathrm{VCaP}$ cells, the BKM120+TKI258 combination elicited the highest amount of PARP cleavage (Figure 4, 22Rv1 lane 9, and Du145 lane 5). Taken together, our CI computation and biochemical data suggests that in prostate cancer a

b

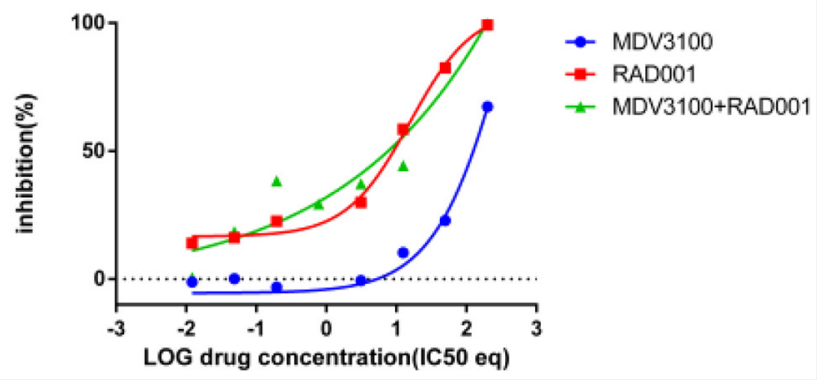

Figure 5: Combination effect of PI3K inhibitors with MDV3100 in the AR negative cell line PC3. PC3 cells were treated with a. MDV3100+BKM120 combination b. MDV3100+RAD001 and analyzed as described in Methods and Figure 3. 
combination of BKM120+TKI258 is perhaps the most effective treatment modality to inhibit the PI3K-pathway resulting in maximum apoptotic response in the tested conditions

Drug-antagonism can impair the efficacy of combination therapy. To further understand the trend towards antagonism observed in the case of BKM120+TKI258 combination (Figure 7h) we carried out a detailed study with increasing drug-concentration ratios in PC3 cells, Table 4. Although synergy is evident across most drug-ratios (CI values 0.03-0.89), it was strongly synergistic at lower concentrations of BKM120 and TKI258 (green boxes in Table 4). As the concentration of each drug increased, the synergy of combined treatment began to decrease with CI values $\geq 1$ (yellow) and, at even higher drug concentrations, the effect shifted predominantly to antagonism (red). Perhaps the drug-target complexes are all completely saturated and thus become a limiting factor, or perhaps the drugs are somehow interacting with each other. Another possibility is that these drugs are no longer completely soluble at such high concentrations, leaving only a fraction of the drug available to inhibit the intended target. Nevertheless, this detailed analysis suggests that the effect of drug combination changes from synergy to antagonism when drug concentrations are increased. Thus, a careful analysis is imperative to designing a combination therapy to yield better response with reduced toxicity.

\section{BKM120+TKI258}

a

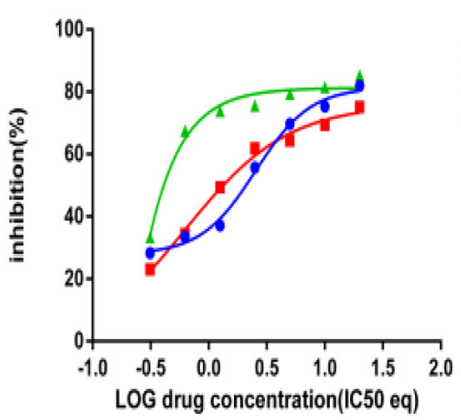

\section{BKM120+RAD001}

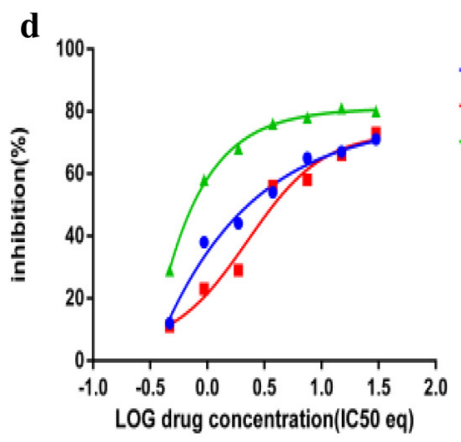

TKI258+RAD001

g

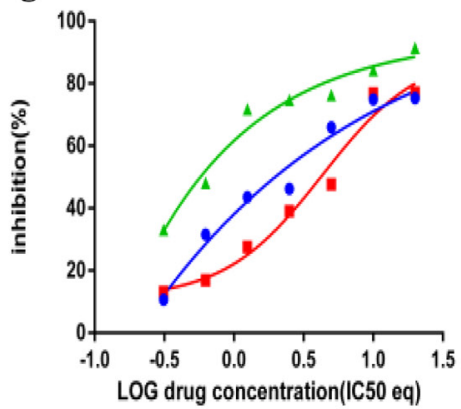

b
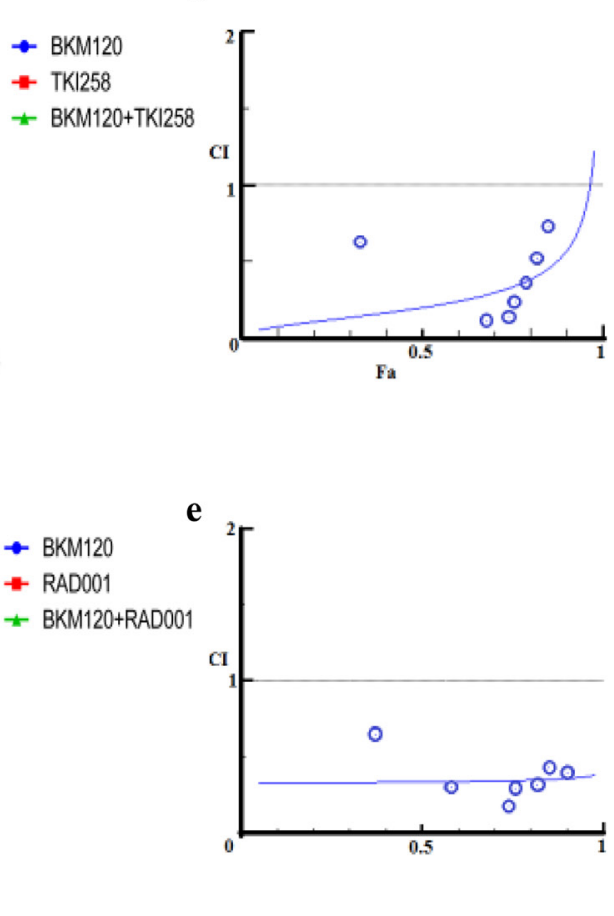

e

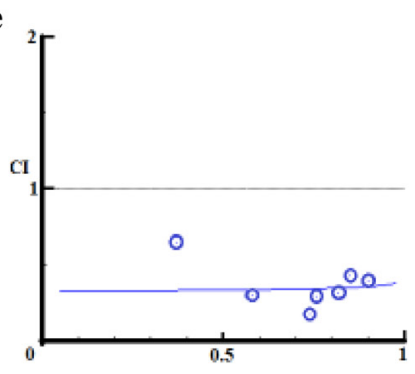

h

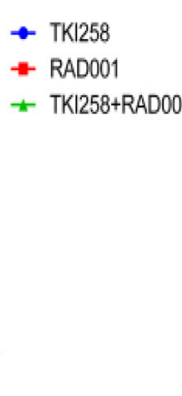

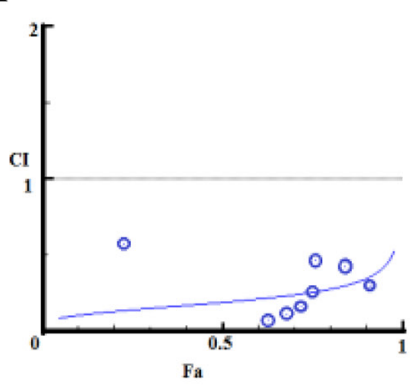

c
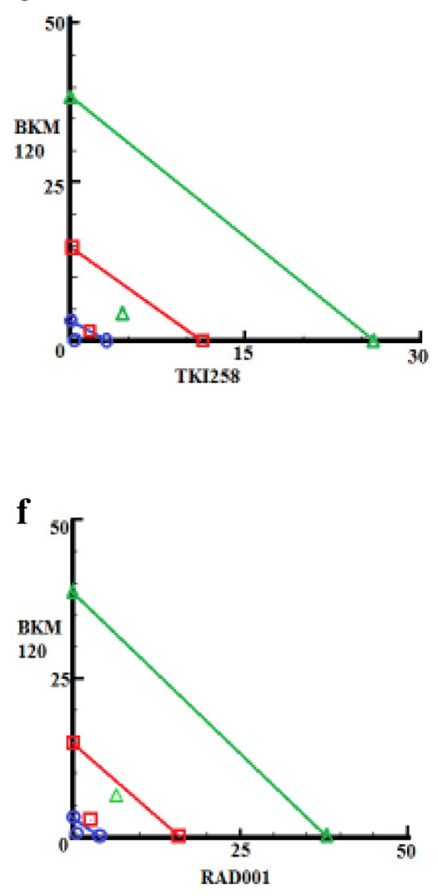

OF $\mathrm{F}=0.5$
$\square \mathrm{Fa}=0.7$

$\triangle \mathrm{Fa}=0.8$

i

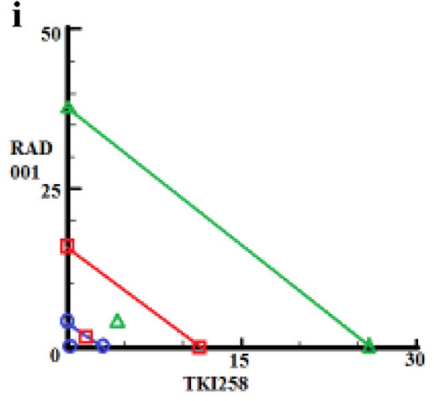

ㅇ $\mathrm{Fa}=0.5$ $\Delta \mathrm{Fa}-0.7$

Figure 6: Combination effect of two drugs that target the PI3K-pathway simultaneously: LNCaP cells were treated with the indicated combination of the drugs and analyzed as described in Methods and Figure 3. 


\section{PC3 cells treated with MDV3100 and BKM120 or RAD001}

Due to the recurrent loss of PTEN in PCa, BKM120, the inhibitor of $\mathrm{PI} 3 \mathrm{~K}$, presents one of the most promising alternatives for $\mathrm{PCa}$ treatments. As mentioned above, the $\mathrm{CI}$ value can change with $\mathrm{Fa}$ and might result in reduced synergy between drugs, especially at high concentrations. To test whether an antagonistic effect existed between MDV3100 and BKM120 (as observed with BKM120 and TKI258 in PC3 cell) or MDV3100 and RAD001, we studied the two-drug combinations in PC3 cells, which have lost both AR and PTEN expression. The curveshift plot in Figure 5a shows that combining BKM120 with MDV3100 is similar to the effect of BKM120 treatment alone. Similarly, the effect of combining
MDV3100+RAD001 is the same as RAD001 alone, albeit slightly lower than BKM120 combination, Figure 5b. Thus, the presence of MDV3100 does not seem to affect the inhibitory property of BKM120 or RAD001.

\section{Effect of combining targeted therapy with chemotherapy}

In addition to testing the combination effect of targeted therapies, we investigated the combination effect of chemotherapy drug cabazitaxel with a PI3K-pathway inhibitor (BKM120, TKI258 or RAD001). Cabazitaxel is FDA approved drug to treat metastatic hormone refractory prostate cancer $[4,34]$. When LNCaP and PC3 cells were treated with a PI3K-pathway inhibitor in combination with Cabazitaxel, comparable levels of

\section{BKM120+RAD001}

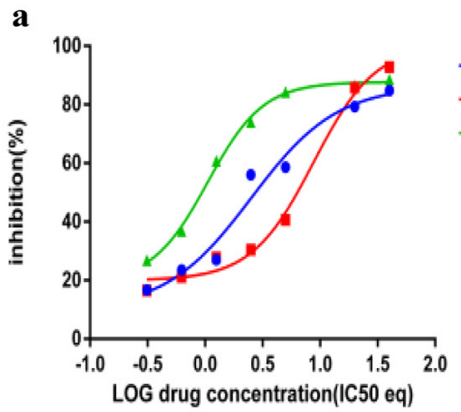

TKI258+RAD001

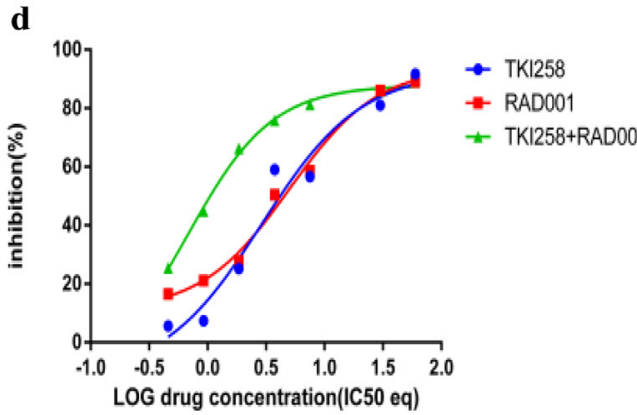

\section{BKM120+TKI258}

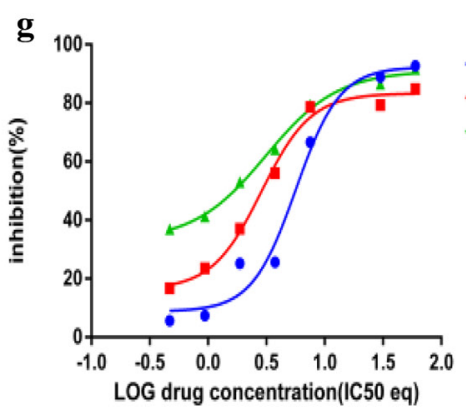

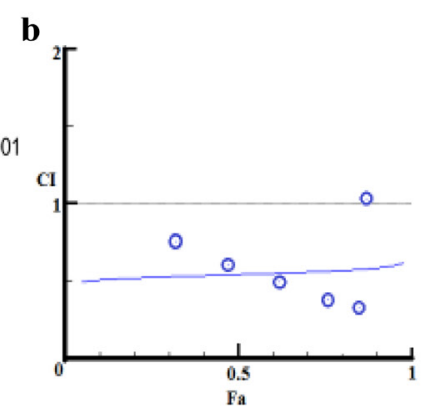

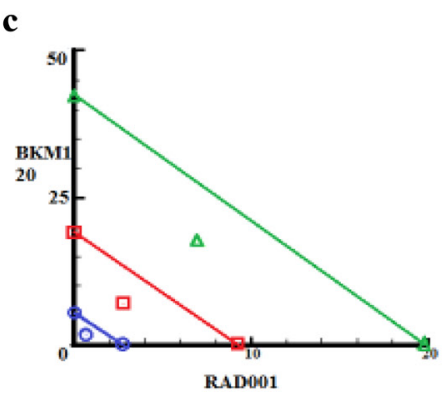

e
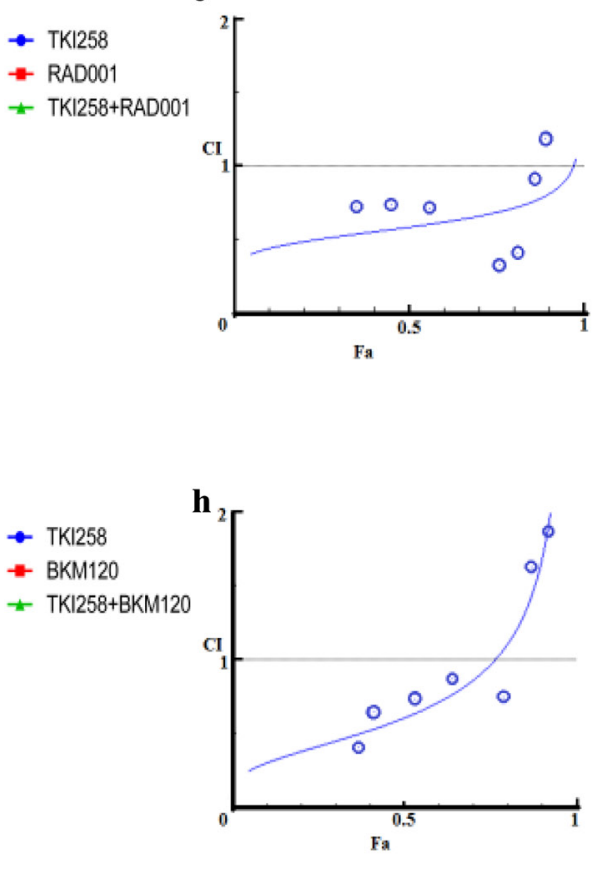

f

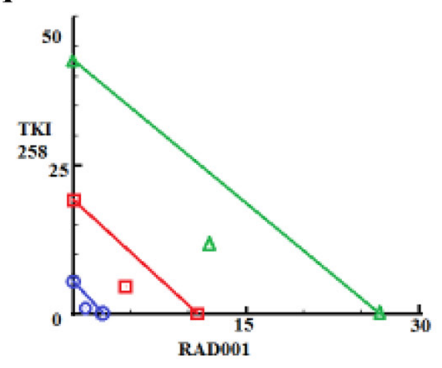

○ $\mathrm{Fa}=0.5$ $\triangle \mathrm{Fa}=0.8$

i

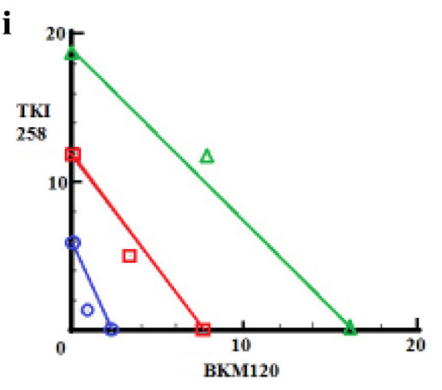

OFa -0.5 $F a=0$

- $\mathrm{F} a=0.5$ 口 $\mathrm{Fa}=0.7$

Figure 7: Combination effect of two drugs that target the PI3K-pathway simultaneously: PC3 cells were treated with the indicated combination of the drugs and analyzed as described in Methods and Figure 3. 
Table 4: Dose response matrix of BKM120+TKI2598 combination in PC3 cells

\begin{tabular}{|c|c|c|c|c|c|c|c|c|c|c|}
\hline & \multicolumn{10}{|c|}{ BKM120 } \\
\hline & $\begin{array}{l}\text { Conc } \\
(\mu \mathrm{M})\end{array}$ & & 50 & 25 & 12.5 & 6.25 & 3.12 & 1.56 & 0.78 & 0.39 \\
\hline \multirow{9}{*}{ TKI258 } & & Viability (\%) & $1 \%$ & $8 \%$ & $36 \%$ & $39 \%$ & $42 \%$ & $64 \%$ & $78 \%$ & $84 \%$ \\
\hline & 50 & $4 \%$ & 3.92 & 2.57 & 1.89 & 1.55 & 1.39 & 1.30 & 1.25 & 1.23 \\
\hline & 25 & $15 \%$ & 2.62 & 1.61 & 1.14 & 0.88 & 0.76 & 0.71 & 0.69 & 0.65 \\
\hline & 12.5 & $26 \%$ & 2.38 & 1.42 & 0.96 & 0.67 & 0.56 & 0.48 & 0.47 & 0.43 \\
\hline & 6.25 & $51 \%$ & 2.29 & 1.33 & 0.75 & 0.49 & 0.34 & 0.28 & 0.24 & 0.24 \\
\hline & 3.12 & $67 \%$ & 2.04 & 1.08 & 0.60 & 0.35 & 0.23 & 0.17 & 0.13 & 0.13 \\
\hline & 1.56 & $76 \%$ & 1.69 & 0.89 & 0.48 & 0.26 & 0.16 & 0.13 & 0.12 & 0.12 \\
\hline & 0.781 & $83 \%$ & 1.54 & 0.78 & 0.39 & 0.21 & 0.14 & 0.11 & 0.09 & 0.26 \\
\hline & 0.39 & $93 \%$ & 1.48 & 0.76 & 0.39 & 0.23 & 0.13 & 0.12 & 0.15 & 0.03 \\
\hline
\end{tabular}

Antagonism $(\mathrm{CI}>1$, red $)$

Additive $(\mathrm{CI}=1$, yellow $)$

Synergism $(\mathrm{CI}<1$, green $)$

synergism were observed in both the cell lines. The CI values ranged between $0.46-0.74$ suggesting moderate to slight synergism (Table 2). In general, the CI value of cabazitaxel in combination with a targeted therapy was higher (less synergistic) than the CI value of two targeted therapies that included one of the same drugs, Table 2 and Figure 8 and 9(a, d, g). Interestingly, however, the cabazitaxel+BKM120 combination in LNCaP cells displayed no trends towards antagonism in the Fa-CI plot and distinct curve shift in the dose-response plot, Figure 8e. Intriguingly, in PC3 cells, the combination of cabazitaxel with BKM120 was more synergistic (CI 0.47) than BKM120+TKI258 (CI 0.77), Figure 8 and Table 2. Taken together, this suggests that using the combination of a PI3K inhibitor, especially BKM120, with cabazitaxel could have treatment benefit beyond that of using cabazitaxel alone. Overall, no significant antagonism was observed with any drug-combination in the PCa cell lines tested.

\section{DISCUSSION}

A complex compensatory crosstalk between the AR- and PI3K-pathways has been identified, limiting the success of single-agent therapy targeting the individual pathways [23, 24, 35]. Indeed clinical trial of single agent RAD001 in chemotherapy-naïve patients showed only a moderate response [21], and all patients on MDV3100 develop disease resistance within 2 years $[20,36]$. Thus, a combined treatment with inhibitors targeting the two pathways could act as a viable alternative [27]. Presently a clinical of combined inhibition of AR- and PI3K pathways, such MDV3100 and RAD001 is underway [37]. Other drugs (such as docetaxel, bicalutamide and ARN509) in combination with RAD001 are also in various phases of early clinical trial $[37,38]$.

Our data suggests that in AR positive conditions (LNCaP and VCaP cells) the BKM120+MDV3100 combination has the most synergistic effect with the ability to induce apoptosis. However, early clinical trail results with BKM120 (inhibitor of PI3K), either alone or with MDV3100, have not been very encouraging [22]. This could because the patients on the trial had already progressed on MDV3100. In this regards, our data suggests that combining BKM120+MDV3100 as first line therapy would be more efficacious than MDV3100 alone. The failure of single-agent PI3K pathway inhibitors suggests the complex and branched nature of the pathway requires better two-stage targeting to completely inhibit it. The focus remains at PI3K, which mediates the activation of AKT, along with mTOR a major effector of the TORC1 complex downstream of AKT. In this regard, our data also suggests that a BKM120+TKI258 combination to be more effective than BKM120+RAD001, and thus could have beneficial effect. Although there is an ongoing trail of BEZ235 (a dual PI3K - mTOR inhibitor) in combination with BKM120 [39], no clinical trial of BKM120+TKI258 in prostate cancer is being carried out.

\section{Antagonism and development of resistance}

Although, at Fa 0.5 (50\% cell death), we saw synergy in all the different combinations, we observed trends towards antagonism at higher Fa values especially 
in the case of BKM120+TKI258. For better therapeutic effect a threshold at $\mathrm{Fa}=0.8$ ( $80 \%$ cell death) is most commonly used when investigating oncogenic drugs [40]. Interestingly, in microbial systems it has been shown paradoxically that antagonistic drug combinations lead to a reduction in the evolution of resistance [28, 41-43]. However, such drug-combination studies and their correlation with resistance-development have not been explored in cancer. This is of particular interest for $\mathrm{PCa}$ as it is a slow-progressing disease with a median age of diagnosis of 65 years. Keeping the tumor burden low or stagnant, with reduced chance of resistance development, than quick elimination of tumor load with increased chance of resistance development and compromised quality of life, could be a viable alternative.
Finally, we found synergistic effect of cabazitaxel in combination with any of the PI3K-pathway inhibitors, most prominently with BKM120 (Table 2). Furthermore, better synergy was observed when MDV3100 was combined with a PI3K-pathway, than when cabazitaxel was combined with the same PI3K-pathway inhibitor. However, similar synergies were observed when twodrugs targeting the PI3K-pathway were used or when a PI3K-pathway inhibiting drug was used in combination with cabazitaxel (Table 2). Taken together our study suggests that addition of $\mathrm{PI} 3 \mathrm{~K} / \mathrm{AKT} / \mathrm{mTOR}$-pathway inhibition especially at the level of PI3K (with drugs such as BKM120) to existing therapies can enhance therapeutic efficacy. The study described here can be used in conjunction with newer techniques of culturing human

\section{Cabazitaxel+TKI258}
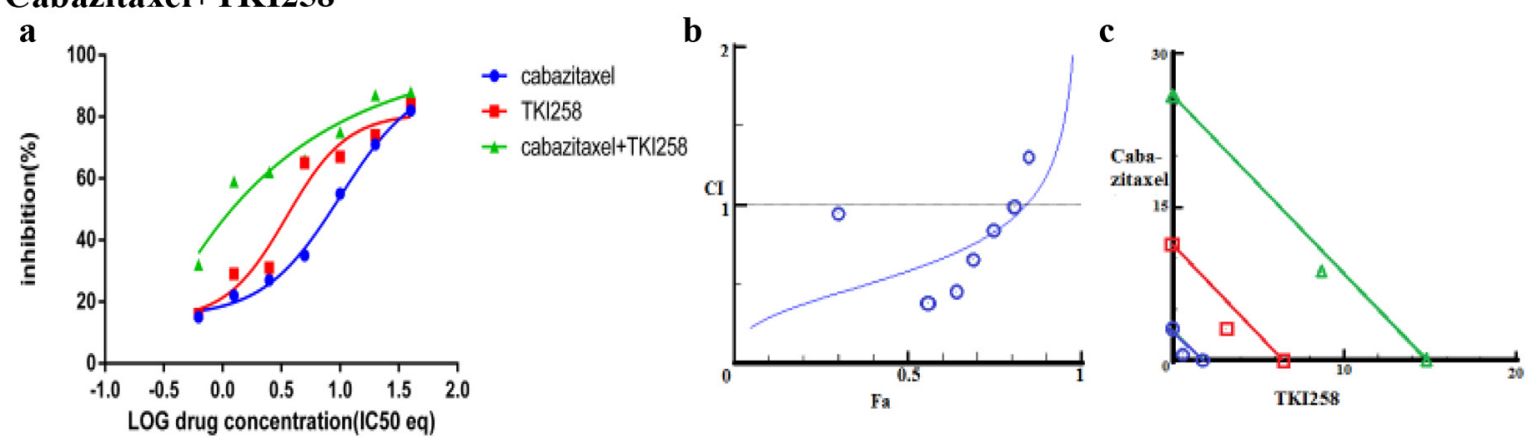

O $\mathrm{F} a-0.5$
$\square \mathrm{F}=0.7$
$\Delta \mathrm{F}=0.8$

\section{Cabazitaxel+BKM120}
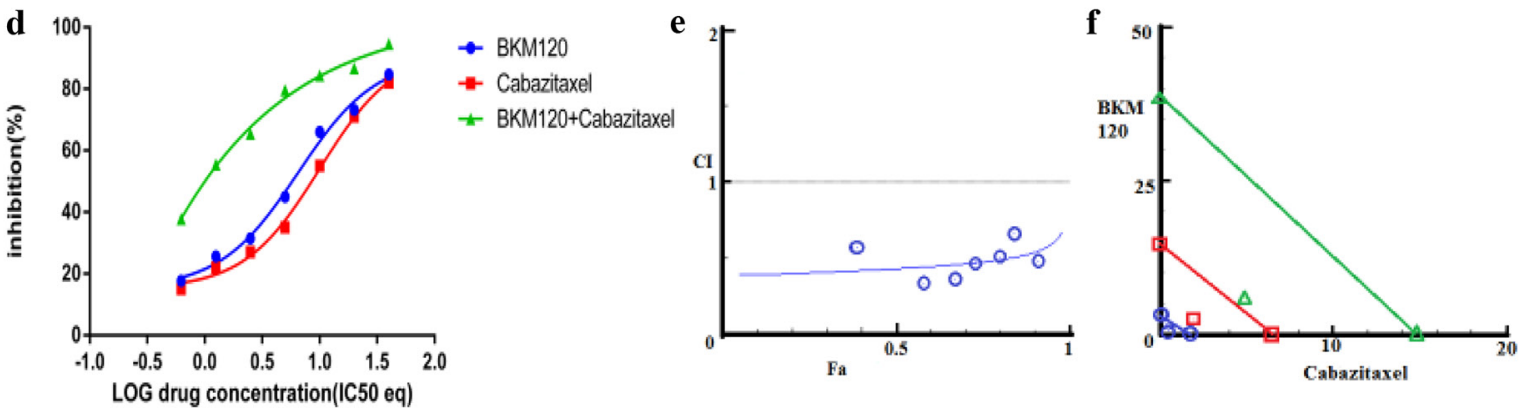

\section{Cabazitaxel+RAD001}

g

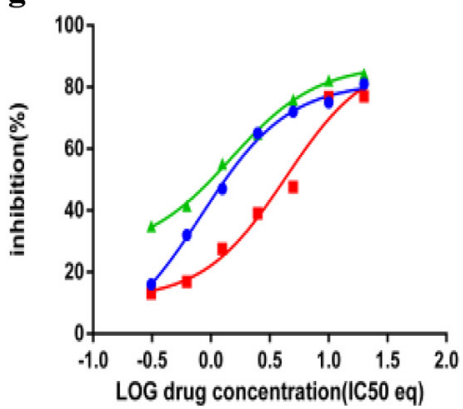

h

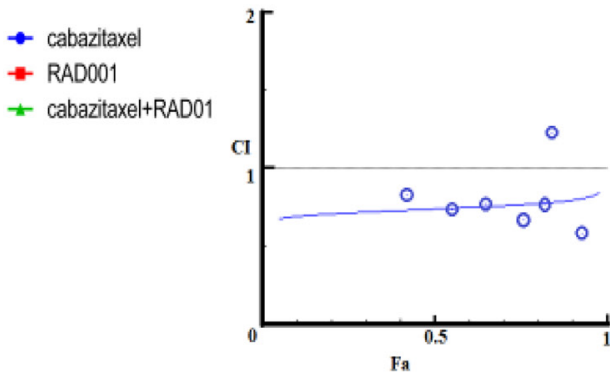

i

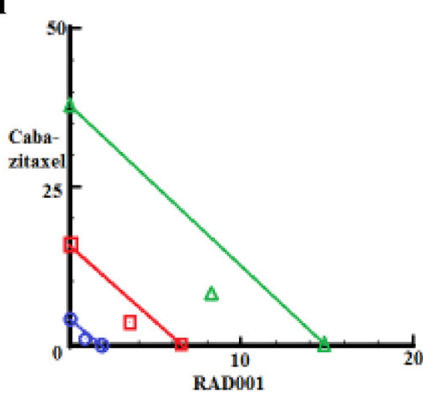

○ $\mathrm{Fa}=0.5$

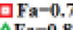
$\triangle \mathrm{Fa}-0.8$

Figure 8: Combination effect of cabazitaxel with drugs that target the PI3K-pathway simultaneously: LNCaP cells were treated with the indicated combination of the drugs and analyzed as described in Methods and Figure 3. 


\section{Cabazitaxel+TKI258}

a

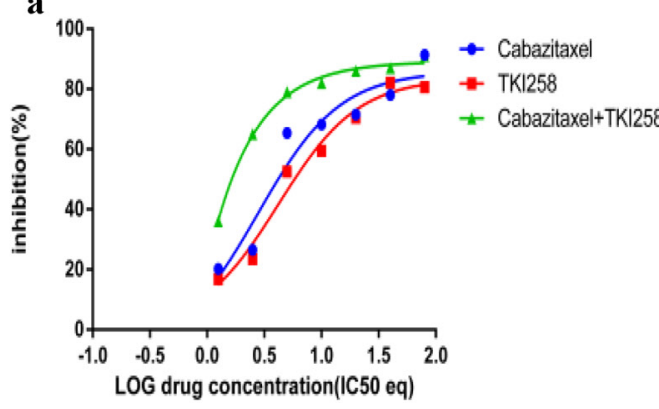

Cabazitaxel+BKM120

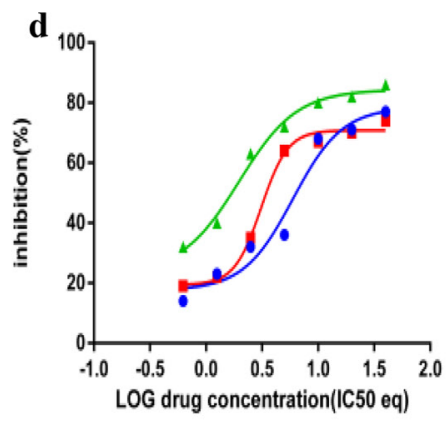

Cabazitaxel+RAD001
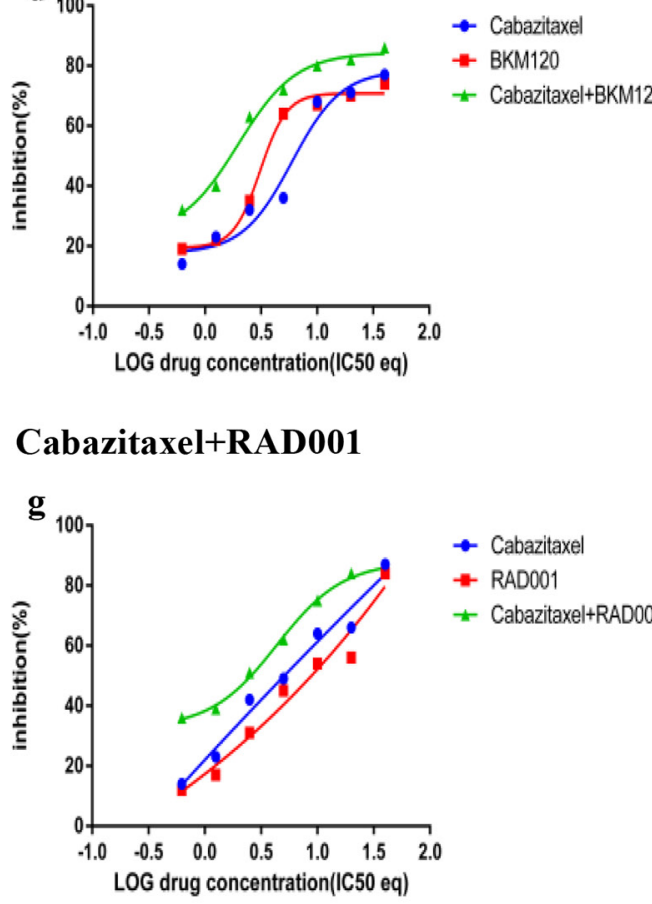

- Cabazitaxel

- BKM120

- Cabazitaxel+BKM120 b

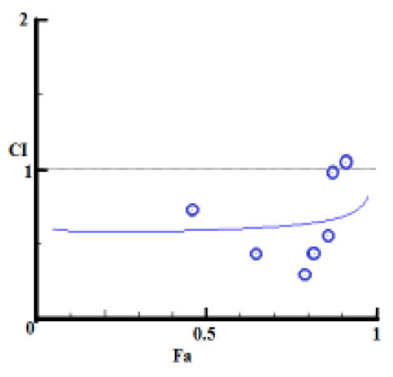

b

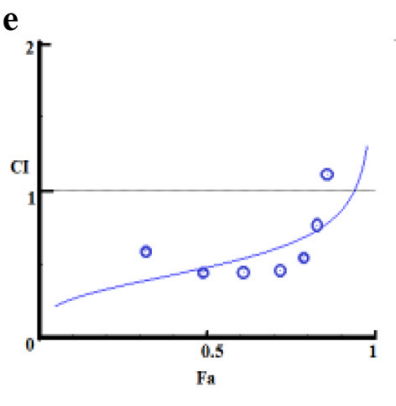

e

f

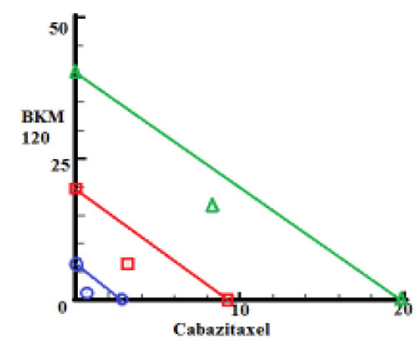

${ }_{258}^{\mathrm{TK}}$

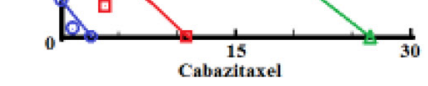

30

O $\mathrm{Fa}=0.5$ $\triangle \mathrm{Fa}=0.7$

Figure 9: Combination effect of cabazitaxel with drugs that target the PI3K-pathway simultaneously: PC3 cells were treated with the indicated combination of the drugs and analyzed as described in Methods and Figure 3.

tumor cells, such as in the form of organoids, to accurately identify best synergistic drug-combinations with potent efficacy and minimal side effects.

\section{MATERIALS AND METHODS}

\section{Cell lines and reagents}

Human prostate cancer cell lines (LNCaP, $\mathrm{VCaP}$, CWR22Rv1 (referred to as 22Rv1), PC3, and Du145) were purchased from American Type Culture Collection (Manassas, VA, USA). RPMI 1640 media, phenol red-free RPMI 1640 media, Fetal Bovine Serum (FBS), Charcoal Stripped FBS One Shot, 1X phosphate buffered saline (PBS) and 100X Antibiotic-Antimycotic (A/A) solutions were purchased from Gibco-Invitrogen Corporation (Carlsbad, CA). Quick Start Bradford 1X dye reagent, 4X Laemmli sample buffer, a Mini Trans-Blot wet transfer system PVDF membranes and non-fat dry milk blocking grade blocker were purchased from Bio-Rad Laboratories (Hercules, CA). cOmplete, EDTA-free Protease Inhibitor Cocktail Tablets were purchased from Roche Diagnostics (Indianapolis, IN). PARP (9542), pAKT (2920), AKT (4691), pS6 (4858) S6 (2317) primary antibodies and secondary anti-mouse IgG (7076) and anti-rabbit (7074) horseradish peroxidase (HRP)-conjugated antibodies were purchased from Cell Signaling Technology, Inc. (Danvers, Massachusetts). Western Bright ECL western blotting detection kit was purchased from Advansta (Menlo Park, CA). 


\section{Cell viability assay}

Cell viability was assessed using the water-soluble tetrazolium salt (WST-1) assay (Clontech) following manufacturer's instructions. 5,000-10,000 cells/well were plated in a 96-well plate and after the cells had adhered the culture media was replaced with drug/s-containing media and cells further incubated for 72 hours. Thereupon, cell viability was assessed using the WST-1 protocol. The cell viability data was used to generate $\mathrm{IC}_{50}$ values using Prism 6 (GraphPad Software Inc, San Diego, USA). Experiments were always set in triplicates and repeated three times.

\section{Drug formulations and treatment}

Buparlisib (BKM120, cat. S2247), Dovitinib (TKI258, cat. S2269), Everolimus (RAD001, cat. S1120), Enzalutamide (MDV3100, cat. S1250) and Cabazitaxel (cat. S3022) were purchased from Selleck Chemicals (Houston, TX, US). All drugs were diluted in dimethyl sulfoxide (DMSO) (Sigma Aldrich, St Louis, MO) and aliquots stored in $-80^{\circ} \mathrm{C}$. Experiments were designed such that none of the inhibitors or inhibitor combinations would completely kill all the cells in any given experiments. The half maximal inhibitory concentration $\left(\mathrm{IC}_{50}\right)$ values of each drug was determined by treating cells with a range of $0.012-200$ $\mu \mathrm{M}$ concentration for three days. For combination studies, $0,1 / 8,1 / 4,1 / 2,1,2$, and 4 times $\mathrm{IC}_{50}$ of each drug and its combination was used in an array format. For BKM120TKI258 studies in PC3 cells, both the drug concentrations ranged from $0-50 \mu \mathrm{M}$ in two-fold increments.

\section{Combination effect analysis}

The fraction of viable cells remaining after three days of drug treatment was normalized to DMSO treated control and plotted against drug concentrations in the logarithmic scale. $\mathrm{IC}_{50}$ values were calculated by performing nonlinear regression analysis using Prism6. Although experiments were set in triplicates and replicated three times, only one set of representative data with the greatest best-fit curve was used for the computation.

\section{Combination index}

The unified theory of using both linear and nonlinear regression analysis, introduced by Chou, was used to evaluate the synergism, additivity and antagonism of the combination drug treatment [40]. Combination index (CI) values were calculated using the CompuSyn software (CompuSyn Inc., Paramus, NJ)[44] which uses the equation:

$$
C I=\frac{C A, x}{I C x, A}+\frac{C B, x}{I C x, B}
$$

Where $\mathrm{CA}, \mathrm{x}$ and $\mathrm{CB}, \mathrm{x}$ are the concentrations of drug $A$ and drug $B$ in the combination to produce a certain effect X. ICx,A and ICx,B are the concentrations of drug $\mathrm{A}$ and drug $\mathrm{B}$ used as a single agent to produce that same effect.

\section{Interpreting drug-combination plots}

CompuSyn also generates a plot of CI values at different fraction affected ( $\mathrm{Fa}$ ) levels referred to as Fa-CI plot or the Chou-Talalay plot, which are widely used to interpret drug combination effects $[40,45]$ and Supplementary Figure $\mathrm{S} 1$. A CI value of $<0.1$ indicates very strong synergism, $0.1-$ 0.3 strong synergism, $0.3-0.7$ synergism, $0.7-0.9$ moderate to slight synergism, 1 nearly additive, $1.1-1.45$ slight to moderate antagonism, 1.45-3.3 antagonism, and $>3.3$ strong to very strong antagonism. The relation of $\mathrm{CI}$ and $\mathrm{Fa}$ is depicted in Supplementary Figure S1A.

To further study the dose-dependent interaction of two drugs' isobolograms, particularly at Fa levels of 50\%, $70 \%$, and $80 \%$ inhibition were created, Supplementary Figure S1B. Since the single agents Fa value corresponds to $\mathrm{IC}_{50}$ value, the $50 \%$ isobologram of the combination provided direct comparison with single agent treatment. The $70 \%$ and $80 \%$ isobologram represent combination at a high effect level and have practical implications in therapeutic oncology [46]. Data points above or below the line of additivity indicate antagonism or synergism, respectively. Finally, to study the nature of inhibition with the drug combinations, a drug-effect-shift analysis of single-agent and combination was carried out, (Supplementary Figure S1C) which allowed for a direct comparison in terms of $\mathrm{IC}_{50}$ equivalents. Here synergy refers to a lowering of $\mathrm{IC}_{50}$ equivalent (left-shift) when compared to single agent curves on the same plot [47], and Supplementary Figure S1C.

\section{Western blot analysis}

Prostate cancer cell lines (LNCaP, VCaP, 22Rv1, PC3, and Du145) were seeded in 12-well tissue culture plates and grown in complete RPMI 1640 media supplemented with $10 \%$ fetal bovine (FBS) and 1\% antibiotic-antimycotic solution (A/A). When cells reached $80 \%$ confluence they were treated with $2 \mathrm{xIC}_{50}$ concentrations of MDV, BKM120, TKI258 or RAD001 alone or in combination for 24 hours. After treatment, excess media was removed and cells were collected and washed with $1 \mathrm{X}$ PBS after dissociation with $0.25 \%$ trypsin. For serum-starved experiments, LNCaP cells were first allowed to attach and grow in complete media until they reached $80 \%$ confluence. Cells were then cultured in phenol red-free RPMI 1640 media supplemented with 5\% charcoal-stripped FBS and 1\% A/A solution for 72 hours prior to treatment with drugs. All cells were maintained at $37^{\circ} \mathrm{C}$ in a humidified atmosphere containing $5 \% \mathrm{CO}_{2}$ (Heracell $^{\mathrm{TM}} 150 \mathrm{i}$ incubator). 
Cell pellets were resuspended in RIPA buffer (50mM Tris, $150 \mathrm{mM} \mathrm{NaCl}, 0.5 \%$ sodium deoxycholate, $1 \%$ NP-40) containing $1 \mathrm{X}$ protease inhibitor cocktail, and lysed by passing them five times through a $28 \mathrm{G} 1 / 2$ needle. After lysis, the homogenates were centrifuged at $4{ }^{\circ} \mathrm{C}$ for $20 \mathrm{~min}$ at $12,000 \mathrm{rpm}$ and the supernatant collected. The protein concentration of the samples was determined by Bradford assay. Equal amounts of protein-lysate $(35 \mu \mathrm{g})$ were separated by SDS-PAGE electrophoresis on $8 \%$ gels for 2 hours at 100V. Following this, separated proteins were electro-transferred at $20 \mathrm{~V}$ to PVDF membranes overnight $\left(4^{\circ} \mathrm{C}\right)$ using a Mini Trans-Blot wet transfer system. The following day membranes were blocked in $1 \mathrm{X}$ TBST $(20 \mathrm{mM}$ Tris- $\mathrm{HCl} \mathrm{pH} 7.6,150 \mathrm{mM} \mathrm{NaCl}$, $0.1 \%$ Tween 20) containing 5\% non-fat milk for 1 hour at room temperature. After blocking, membranes were incubated with primary antibodies as per manufacturer recommendations overnight at $4{ }^{\circ} \mathrm{C}$, followed by washing with $1 \mathrm{X}$ TBST ( 3 times $\mathrm{x} 5$ minutes each) and probing with secondary HRP-conjugated anti-mouse or antirabbit antibodies (1:5000 dilution) for 1 hour at room temperature. After a final step of washing, proteins were visualized using Western Bright ECL detection kit reagents under a digital scanner Image Quant LAS 4000 by GE.

\section{ACKNOWLEDGMENTS}

We are thankful to Dr. Tarun Kapoor (Rockefeller University, New York) for help in initializing the project, and use of his lab space and resources. We are also thankful to the Department of Hematology and Oncology, Icahn School of Medicine at Mount Sinai, New York for use of their equipment and resources. Both SSY and KKY thank the Prostate Cancer Foundation for Young Investigator Awards.

\section{CONFLICTS OF INTEREST}

None.

\section{GRANT SUPPORT}

The research work was supported by funds from the Prostate Cancer Foundation and Deane Prostate Health, Icahn School of Medicine at Mount Sinai, NY

\section{REFERENCES}

1. website N. http://seer.cancer.gov/statfacts/html/prost.html.

2. Hotte SJ and Saad F. Current management of castrateresistant prostate cancer. Curr Oncol. 2010; 17:S72-79.

3. Stuyckens K, Saad F, Xu XS, Ryan CJ, Smith MR, Griffin TW, Yu MK, Vermeulen A, Nandy P and Poggesi I. Population pharmacokinetic analysis of abiraterone in chemotherapy-naive and docetaxel-treated patients with metastatic castration-resistant prostate cancer. Clin Pharmacokinet. 2014; 53:1149-1160.

4. Lee JL, Park SH, Koh SJ, Lee SH, Kim YJ, Choi YJ, Lee $\mathrm{J}$ and Lim HY. Effectiveness and safety of cabazitaxel plus prednisolone chemotherapy for metastatic castrationresistant prostatic carcinoma: data on Korean patients obtained by the cabazitaxel compassionate-use program. Cancer Chemother Pharmacol. 2014; 74:1005-1013.

5. Taylor BS, Schultz N, Hieronymus H, Gopalan A, Xiao Y, Carver BS, Arora VK, Kaushik P, Cerami E, Reva B, Antipin Y, Mitsiades N, Landers T, Dolgalev I, Major JE, Wilson $\mathrm{M}$, et al. Integrative genomic profiling of human prostate cancer. Cancer Cell. 2010; 18:11-22.

6. Robinson D, Van Allen EM, Wu YM, Schultz N, Lonigro RJ, Mosquera JM, Montgomery B, Taplin ME, Pritchard CC, Attard G, Beltran H, Abida W, Bradley RK, Vinson $\mathrm{J}$, Cao X, Vats $\mathrm{P}$, et al. Integrative clinical genomics of advanced prostate cancer. Cell. 2015; 161:1215-1228.

7. Cancer Genome Atlas Research Network. Electronic address scmo and Cancer Genome Atlas Research N. The Molecular Taxonomy of Primary Prostate Cancer. Cell. 2015; 163:1011-1025.

8. Scher HI and Sawyers CL. Biology of progressive, castration-resistant prostate cancer: directed therapies targeting the androgen-receptor signaling axis. J Clin Oncol. $2005 ; 23: 8253-8261$.

9. Scher HI, Fizazi K, Saad F, Taplin ME, Sternberg CN, Miller K, de Wit R, Mulders P, Chi KN, Shore ND, Armstrong AJ, Flaig TW, Flechon A, Mainwaring P, Fleming M, Hainsworth JD, et al. Increased survival with enzalutamide in prostate cancer after chemotherapy. N Engl J Med. 2012; 367:1187-1197.

10. Golshayan AR and Antonarakis ES. Enzalutamide: an evidence-based review of its use in the treatment of prostate cancer. Core Evid. 2013; 8:27-35.

11. Dumas L, Payne $\mathrm{H}$ and Chowdhury S. The evolution of antiandrogens: MDV3100 comes of age. Expert Rev Anticancer Ther. 2012; 12:131-133.

12. Noonan KL, North S, Bitting RL, Armstrong AJ, Ellard SL and Chi KN. Clinical activity of abiraterone acetate in patients with metastatic castration-resistant prostate cancer progressing after enzalutamide. Ann Oncol. 2013; 24:1802-1807.

13. Morgan TM, Koreckij TD and Corey E. Targeted therapy for advanced prostate cancer: inhibition of the PI3K/ Akt/mTOR pathway. Curr Cancer Drug Targets. 2009; 9:237-249.

14. Grasso CS, Wu YM, Robinson DR, Cao X, Dhanasekaran SM, Khan AP, Quist MJ, Jing X, Lonigro RJ, Brenner JC, Asangani IA, Ateeq B, Chun SY, Siddiqui J, Sam L, Anstett M, et al. The mutational landscape of lethal castration-resistant prostate cancer. Nature. 2012; 487:239-243. 
15. Chang L, Graham PH, Hao J, Ni J, Bucci J, Cozzi PJ, Kearsley $\mathrm{JH}$ and $\mathrm{Li} \mathrm{Y}$. PI3K/Akt/mTOR pathway inhibitors enhance radiosensitivity in radioresistant prostate cancer cells through inducing apoptosis, reducing autophagy, suppressing NHEJ and HR repair pathways. Cell Death Dis. 2014; 5:e1437.

16. Wan X, Corn PG, Yang J, Palanisamy N, Starbuck MW, Efstathiou E, Tapia EM, Zurita AJ, Aparicio A, Ravoori MK, Vazquez ES, Robinson DR, Wu YM, Cao X, Iyer MK, McKeehan W, et al. Prostate cancer cell-stromal cell crosstalk via FGFR1 mediates antitumor activity of dovitinib in bone metastases. Sci Transl Med. 2014; 6:252ra122.

17. Courtney KD, Manola JB, Elfiky AA, Ross R, Oh WK, Yap JT, Van den Abbeele AD, Ryan CW, Beer TM, Loda M, Priolo C, Kantoff P and Taplin ME. A phase I study of everolimus and docetaxel in patients with castration-resistant prostate cancer. Clin Genitourin Cancer. 2015; 13:113-123.

18. Lee CK, Lee ME, Lee WS, Kim JM, Park KH, Kim TS, Lee KY, Ahn JB, Chung HC and Rha SY. Dovitinib (TKI258), a multi-target angiokinase inhibitor, is effective regardless of KRAS or BRAF mutation status in colorectal cancer. Am J Cancer Res. 2015; 5:72-86.

19. Dey JH, Bianchi F, Voshol J, Bonenfant D, Oakeley EJ and Hynes NE. Targeting fibroblast growth factor receptors blocks PI3K/AKT signaling, induces apoptosis, and impairs mammary tumor outgrowth and metastasis. Cancer Res. 2010; 70:4151-4162.

20. Beer TM, Armstrong AJ, Rathkopf DE, Loriot Y, Sternberg $\mathrm{CN}$, Higano CS, Iversen P, Bhattacharya S, Carles J, Chowdhury S, Davis ID, de Bono JS, Evans CP, Fizazi $\mathrm{K}$, Joshua AM, Kim CS, et al. Enzalutamide in metastatic prostate cancer before chemotherapy. N Engl J Med. 2014; 371:424-433.

21. Templeton AJ, Dutoit V, Cathomas R, Rothermundt C, Bartschi D, Droge C, Gautschi O, Borner M, Fechter E, Stenner F, Winterhalder R, Muller B, Schiess R, Wild PJ, Ruschoff JH, Thalmann G, et al. Phase 2 trial of singleagent everolimus in chemotherapy-naive patients with castration-resistant prostate cancer (SAKK 08/08). Eur Urol. 2013; 64:150-158.

22. Andrew J. Armstrong SH, Patrick Healy, Joshi J. Alumkal, Evan Y. Yu, Carolyn Winters, Carey Hobbs, Colleen Soleau, Rachel Slottke, Kelly Mundy, Daniel J. George. Phase II trial of the PI3 kinase inhibitor BKM120 with or without enzalutamide in men with metastatic castration resistant prostate cancer (mCRPC). ASCO meeting. 2015.

23. Carver BS, Chapinski C, Wongvipat J, Hieronymus H, Chen Y, Chandarlapaty S, Arora VK, Le C, Koutcher J, Scher H, Scardino PT, Rosen N and Sawyers CL. Reciprocal feedback regulation of $\mathrm{PI} 3 \mathrm{~K}$ and androgen receptor signaling in PTEN-deficient prostate cancer. Cancer Cell. 2011; 19:575-586.

24. Mulholland DJ, Tran LM, Li Y, Cai H, Morim A, Wang S, Plaisier S, Garraway IP, Huang J, Graeber TG and Wu H. Cell autonomous role of PTEN in regulating castration-resistant prostate cancer growth. Cancer Cell. 2011; 19:792-804.
25. Yardley DA. Drug resistance and the role of combination chemotherapy in improving patient outcomes. Int J Breast Cancer. 2013; 2013:137414.

26. Toren P, Kim S, Cordonnier T, Crafter C, Davies BR, Fazli L, Gleave ME and Zoubeidi A. Combination AZD5363 with Enzalutamide Significantly Delays Enzalutamide-resistant Prostate Cancer in Preclinical Models. Eur Urol. 2015; 67:986-990.

27. Thomas C, Lamoureux F, Crafter C, Davies BR, Beraldi E, Fazli L, Kim S, Thaper D, Gleave ME and Zoubeidi A. Synergistic targeting of PI3K/AKT pathway and androgen receptor axis significantly delays castration-resistant prostate cancer progression in vivo. Mol Cancer Ther. 2013; 12:2342-2355.

28. Yeh PJ, Hegreness MJ, Aiden AP and Kishony R. Drug interactions and the evolution of antibiotic resistance. Nat Rev Microbiol. 2009; 7:460-466.

29. Jia J, Zhu F, Ma X, Cao Z, Li Y and Chen YZ. Mechanisms of drug combinations: interaction and network perspectives. Nat Rev Drug Discov. 2009; 8:111-128.

30. Kuruma H, Matsumoto H, Shiota M, Bishop J, Lamoureux F, Thomas C, Briere D, Los G, Gleave M, Fanjul A and Zoubeidi A. A novel antiandrogen, Compound 30, suppresses castration-resistant and MDV3100-resistant prostate cancer growth in vitro and in vivo. Mol Cancer Ther. 2013; 12:567-576.

31. Tanaka H, Yoshida M, Tanimura H, Fujii T, Sakata K, Tachibana Y, Ohwada J, Ebiike H, Kuramoto S, Morita K, Yoshimura Y, Yamazaki T, Ishii N, Kondoh O and Aoki Y. The selective class I PI3K inhibitor CH5132799 targets human cancers harboring oncogenic PIK3CA mutations. Clin Cancer Res. 2011; 17:3272-3281.

32. Tewari M, Quan LT, O'Rourke K, Desnoyers S, Zeng Z, Beidler DR, Poirier GG, Salvesen GS and Dixit VM. Yama/CPP32 beta, a mammalian homolog of CED-3, is a CrmA-inhibitable protease that cleaves the death substrate poly(ADP-ribose) polymerase. Cell. 1995; 81:801-809.

33. Tepper CG, Boucher DL, Ryan PE, Ma AH, Xia L, Lee LF, Pretlow TG and Kung HJ. Characterization of a novel androgen receptor mutation in a relapsed CWR22 prostate cancer xenograft and cell line. Cancer Res. 2002; 62:6606-6614.

34. Abidi A. Cabazitaxel: A novel taxane for metastatic castrationresistant prostate cancer-current implications and future prospects. J Pharmacol Pharmacother. 2013; 4:230-237.

35. Liu L and Dong X. Complex impacts of PI3K/AKT inhibitors to androgen receptor gene expression in prostate cancer cells. PLoS One. 2014; 9:e108780.

36. Sternberg CN, de Bono JS, Chi KN, Fizazi K, Mulders P, Cerbone L, Hirmand M, Forer D and Scher HI. Improved outcomes in elderly patients with metastatic castrationresistant prostate cancer treated with the androgen receptor inhibitor enzalutamide: results from the phase III AFFIRM trial. Ann Oncol. 2014; 25:429-434. 
37. https://clinicaltrials.gov/ct2/show/NCT02125084?term $=$ en zalutamide+everolimus\&rank $=1$.

38. https://clinicaltrials.gov/ct2/results?term=everolimus+AND + prostate + cancer\&Search $=$ Search .

39. https://clinicaltrials.gov/ct2/show/study/NCT01634061?ter $\mathrm{m}=\mathrm{bkm} 120+\mathrm{AND}+$ prostate + cancer \&rank $=4$.

40. Chou TC. Drug combination studies and their synergy quantification using the Chou-Talalay method. Cancer Res. 2010; 70:440-446.

41. Hegreness M, Shoresh N, Damian D, Hartl D and Kishony R. Accelerated evolution of resistance in multidrug environments. Proc Natl Acad Sci U S A. 2008; 105:13977-13981.

42. Michel JB, Yeh PJ, Chait R, Moellering RC, Jr. and Kishony R. Drug interactions modulate the potential for evolution of resistance. Proc Natl Acad Sci U S A. 2008; 105:14918-14923.

43. Baym M, Stone LK and Kishony R. Multidrug evolutionary strategies to reverse antibiotic resistance. Science. 2016; 351:aad3292.

44. ComboSyn Iw. combosyn software. 2014.

45. Tallarida RJ. Drug synergism: its detection and applications. J Pharmacol Exp Ther. 2001; 298:865-872.

46. Pu YS, Chen J, Huang CY, Guan JY, Lu SH and Hour TC. Cross-resistance and combined cytotoxic effects of paclitaxel and cisplatin in bladder cancer cells. J Urol. 2001; 165:2082-2085.

47. Zhao L, Au JL and Wientjes MG. Comparison of methods for evaluating drug-drug interaction. Front Biosci (Elite Ed). $2010 ; 2: 241-249$. 